\title{
Esquizo-ocupação: uma ferramenta de análise da instituição Terapia Ocupacional
}

\author{
'Schizo-occupation': a tool for the analysis of the \\ institution Occupational Therapy
}

\author{
Marcia Cabral da Costa ${ }^{1}$, Marcus Vinícius Machado de Almeida ${ }^{2}$
}

\begin{abstract}
COSTA M. C.; ALMEIDA, M. V. M. Esquizo-ocupação: uma ferramenta de análise da instituição Terapia Ocupacional. Rev. Ter. Ocup. Univ. São Paulo, v. 15, n. 1, p. 11-6, jan./abr., 2004.

RESUMO: O presente artigo propõe o conceito-exercício 'esquizo-ocupação' como uma ferramenta de análise para problematizar a instituição 'Terapia Ocupacional'. Inspirada na esquizoanálise e na análise de como a instituição 'terapia ocupacional' vem se constituindo enquanto um campo de saber, o conceito-exercício 'esquizo-ocupação' não será proposto como um Modelo dotado de verdades, direcionador de técnicas e/ou procedimentos, mas sim como uma ferramenta de análise a ser operada quotidianamente na terapia ocupacional. A utilização desta ferramenta visa a possibilitar a emergência de posicionamentos éticos e políticos em uma profissão compromissada com o social e não a serviço de interesses hegemônicos. Com isto, o conceito-exercício 'esquizoocupação’ será tomado para instigar no terapeuta ocupacional uma visão caleidoscópica sobre as atividades, os modelos e os métodos. Uma provocação para desnaturalizar, para estranhar as habituais análises de atividades. Uma provocação que se propõe a compor múltiplos olhares, múltiplos sentidos da terapia ocupacional.
\end{abstract}

DESCRITORES: Terapia Ocupacional/ tendências.Prática profissional/tendências. Psicanálise/ tendências.

\footnotetext{
${ }^{1}$ Terapeuta Ocupacional do Instituto Municipal Nise da Silveira e do Centro Psiquiátrico do Rio de Janeiro; Especialista em Clínica Transdisciplinar e Instituições Públicas pela UFF-RJ; Mestranda em Psicologia - Estudos da Subjetividade/UFF-RJ.

${ }^{2}$ Terapeuta Ocupacional e Musicoterapeuta; Docente do Departamento de Arte Corporal da UFRJ; Mestre em História e Crítica da Arte/UFRJ e Doutorando em Pedagogia do Movimento-Corporeidade/ UNICAMP-SP.

Endereço para correspondência: Rua Teodoro da Silva, 327/102 - Vila Isabel, Rio de Janeiro, RJ. CEP: 20560-000. e-mail: marciacabralto@globo.com e marcusvmachado@globo.com
} 
$\mathrm{N}$ osso trabalho tem como caminho a produção do conceito-exercício de 'esquizo-ocupação' como uma ferramenta para colocar em análise a instituição Terapia Ocupacional. Esta análise, em nossa avaliação, faz-se necessária uma vez que, ao acompanharmos historicamente a constituição da terapia ocupacional em seu universo clínico e conceitual, pudemos inferir na própria terapia ocupacional pontos que consideramos relevantes, bem como aqueles que consideramos aprisionantes. Assim, a esquizo-ocupação se propõe a ser um exercício, um meio possível de potencializar o que há de intenso na terapia ocupacional. Para seguir o caminho da construção deste conceitoexercício, partiremos de algumas problematizações fazendo uso de uma série de questionamentos no campo da terapia ocupacional como o campo de identidade, o campo de saberes especializados, o campo de uma clínica específica.

Para chegar ao conceito-exercício de esquizoocupação, construiremos neste texto uma trajetória que coloca em evidência algumas noções importantes para a análise da instituição Terapia Ocupacional.

Tomaremos, em primeiro lugar, a noção de campo, noção que define especificidades como o campo da terapia ocupacional. A noção de campo tal como definiu Kurt Lewin (apud PASSOS; BARROS, 2000) nos remete a pensar 'campo' como fronteira que separa os saberes entre si mesmos, ratificando identidades e saberes especializados. Isto é, a noção de campo porta uma lógica binária que afirma algo a partir da negação de outros elementos de uma relação. Em nossos questionamentos sobre o campo da terapia ocupacional, temos entendido que a noção de campo pode produzir modos de exclusão, na medida em que impõe a necessidade de delimitar seus saberes e práticas. Esta exclusão pode ser da ordem da diversidade de atividades, da multiplicidade do uso de materiais, da seleção de certos clientes com este ou aquele diagnóstico — questões que atravessam cotidianamente em nossas experiências clínicas e que se colocam, muitas vezes de forma invisível e indizível.

Estes mecanismos, de invisibilidade e de indizibilidade, podem despotencializar as múltiplas forças que são passíveis de compor uma clínica na terapia ocupacional. Em nosso cotidiano nos deparamos freqüentemente com relevantes experiências da clínica em terapia ocupacional que nem sempre são configuradas, ou reconhecidas dentro de um modelo teórico já consagrado. Isto tem levado alguns a refutar tais experiências e buscar 'enquadrar' estas experiências em campos conceituais já conhecidos como: a psicanálise, a psicologia analítica, o holismo etc. Pensamos que a busca desses campos conceituais legitimados traduz um mecanismo que pretende consagrar a prática do terapeuta ocupacional, ou seja, pretende produzir uma identidade estática para a terapia ocupacional. Entretanto, esta produção de uma identidade para a terapia ocupacional nem sempre age a favor de seu reconhecimento. A terapia ocupacional, por transitar em diversas linguagens, pensamentos, pode de alguma forma produzir, em sua clínica, diferenças. Diferenças às vezes sutis que podem afirmar, para alguns, um campo identitário da terapia ocupacional. A potencialização da diferença na terapia ocupacional deve produzir o abortamento desta intenção de 'enquadramento' da terapia ocupacional nos modelos teórico-clínicos consagrados. A diferença que pretendemos na terapia ocupacional supõe uma sublevação contra a hegemonia de certos saberes e a favor de parcerias com saberes diversos, científicos ou não, consagrados ou não. Contudo, caracterizamos esta diferença como processo de singularização, como ato de diferir; e não como constatação de uma identidade do diferente. Guattari (1993, p. 80) nos mostra que "não há primado de um sistema de modelização sobre os outros. (...) Todas as modelizações, potencialmente, se equivalem". É por isto que, ao invés de preferirmos uma certa identidade da terapia ocupacional como um saber consagrado diferente, preferimos o diferir da terapia ocupacional, isto é sua capacidade constante de criar novos modos de operar sua clínica, escapando assim das amarras dos modelos consagrados. Este é o primeiro passo para irmos construindo o conceito-exercício de esquizo-ocupação.

Ao recusarmos a noção de 'campo' por sua lógica binária e dicotômica, propomos a noção de 'plano' pelo fato de esta noção guardar a potência da multiplicidade, por apresentar-se como uma zona de interferências que não exclui seus elementos mutuamente, mas os intensifica nos encontros. Nesta opção pela noção de plano, com seus atravessamentos, somos levados ao encontro com a clínica a que estamos chamando de transdisciplinar. Uma clínica com "componentes teóricos e tecnológicos, mas também estéticos, éticos, econômicos, políticos e afetivos que se atravessam neste plano, impulsionando seu mecanismo de produção de realidade, seja ela objetiva ou subjetiva" (PASSOS; BARROS, 2000, p. 76). É importante ressaltar que nossa escolha pela clínica transdisciplinar inevitavelmente nos coloca numa atitude não hierárquica e não seletiva que direciona a nossa clínica para caminhos não conhecidos. A clínica transdisciplinar coloca-nos numa relação de bricolagem 
com fragmentos provenientes de múltiplos componentes teóricos e metodológicos.

A partir de nossas leituras e contatos com a esquizoanálise e com os múltiplos modos de fazer a clínica da terapia ocupacional, formulamos o conceitoexercício de esquizo-ocupação. Este refere-se à produção dos múltiplos modos de se fazer a clínica em terapia ocupacional, sob a condição de colocar esses múltiplos modos em constante análise de seus efeitos, potencializando a multiplicidade. Essas análises não se referem ao sentido restrito que nós terapeutas ocupacionais temos habitualmente nomeado de 'análise de atividades' sob quaisquer das perspectivas teóricas conhecidas, sejam elas positivistas, marxistas, humanistas, holísticas. Referem-se fundamentalmente ao sentido de cartografar os efeitos clínicos, políticos, econômicos, estéticos, éticos que nossa intervenção terapêutica ocupacional, nossos usos das atividades e fazeres têm produzido a cada momento. A esquizoocupação é o exercício de colocar a instituição da terapia ocupacional em análise. Talvez seja necessário esclarecermos, agora, o que estamos denominando de instituição.

'Instituição' para nós tem o entendimento atribuído pela Análise Institucional. Distinguindo do mero entendimento da 'instituição' enquanto 'estabelecimento', enquanto estrutura física de um órgão, a 'instituição' é vista como "um campo de forças que legitimam valores e modelos hegemônicos, [como] um inconsciente político que institui novas realidades sempre dividindo, sempre separando" (RODRIGUES; SOUZA, 1987). Sendo assim, poderemos falar da instituição 'família', da instituição 'escola', da instituição 'psicanálise', da instituição ‘terapia ocupacional'.

Se entendermos instituição como um campo de práticas múltiplas e heterogêneas que são organizadas e legitimadas socialmente e que por isso deve ser colocada em análise, posta a ser desconstruída para a construção de novas práticas, pensamos que esse entendimento de instituição nos serve para a construção de uma atitude ética, estética e política na terapia ocupacional.

Abordando a esquizo-ocupação como um conceito-exercício de colocar em análise a instituição da terapia ocupacional, parece-nos necessário fazer um breve comentário sobre a esquizoanálise. A esquizoanálise surgiu no início da década de 1970 a partir do encontro e parceria de trabalho entre o filósofo Gilles Deleuze e Félix Guattari, psicanalista e militante marxista. O propósito da esquizo-ocupação é questionar o caráter científico e estrutural dos operadores psicanalíticos (GUATTARI, 1993).
Com o intuito de problematizar a instituição 'Psicanálise' até então forma hegemônica de intervenção clínica na saúde mental, a esquizoanálise viria desestabilizar o entendimento da psicanálise como procedimento privilegiado de se fazer clínica (BAREMBLITT, 1998). Originalmente a psicanálise teve seu modelo clínico estruturado a partir da neurose, e isto colocava um problema na operação clínica com outras formas de subjetividade, como a esquizofrenia. As bases abaladas da psicanálise só eram sentidas na medida em que os efeitos clínico-políticos se mostravam precários para a população (essencialmente os esquizofrênicos asilados). "A cisão metodológica entre o que se poderia chamar uma esquizoanálise e as práticas analíticas tradicionais reside essencialmente no fato de que a perspectiva esquizoanalítica rompe com os paradigmas científicos, para fazer passar todas as produções de subjetividade sob a égide de paradigmas ético-pragmáticos, ético-estéticos" (GUATTARI, 1993, p. 79).

Assim, em sintonia com a esquizoanálise, a esquizo-ocupação ganha relevância na medida em que propõe questionamentos sobre práticas já instituídas da terapia ocupacional. Mais do que naturalizar o uso das atividades como eficientes na clínica da terapia ocupacional, é preciso uma atitude de nos colocarmos em análise a todo o tempo, produzindo sempre novas cartografias, novos mapeamentos acerca do que o uso das atividades e dos distintos fazeres têm produzido nos modos de subjetivação. O uso das atividades em nosso cotidiano profissional tem produzido novos territórios existências ou tem produzido existências aprisionadas em modelos hegemônicos, em comportamentos 'adestrados' pelos interesses majoritários?

O conceito-exercício de esquizo-ocupação não poderá, portanto, ser compreendido como um novo modelo ou método da terapia ocupacional, nem mesmo como uma nova técnica. Devemos tomá-lo como um exercício crítico sobre os nossos fazeres, sobre o que produzimos como clínica, ou melhor, o que produzimos socialmente. Pensamos ser necessário este exercício por percebermos nas práticas da terapia ocupacional fundamentalmente dois procedimentos: um referido a uma empiria destituída da necessária problematização dos seus efeitos; e o outro, referido à excessiva sujeição das práticas em relação a campos teóricos geralmente pautados em concepções científicas consagradas. $\mathrm{O}$ que temos avaliado é que esses dois procedimentos podem produzir, ora uma desvalorização do profissional terapeuta ocupacional por ele mesmo não produzir reflexões e não saber comunicar os efeitos de sua intervenção clínica, colocando a terapia ocupacional 
como indizível, invisibilizando-a, conseqüentemente ora um posicionamento que o demarca como profissional 'científico', que, no entanto, nem sempre produz efeitos de uma clínica intensa. Para nós, efeitos clínicos intensos são produções do plano da vida, da criação de novos modos de viver, de pensar e de sentir. Esta observação parece ser partilhada por outros pesquisadores da clínica como Rauter (1998, p. 5). "Quando as próprias ciências ditas exatas já abandonaram a pretensão de um saber que pudesse abarcar todos os fenômenos ou legislar sobre a natureza, a busca de modelos científicos tem paralisado, em grande parte, a experimentação no campo da clínica. Não pensamos a prática clínica como técnica sustentada por um corpo teórico do qual esta seria "aplicação"'. Pensamos que a esquizo-ocupação pode favorecer a possibilidade de avaliarmos o quanto os distintos fazeres se engendram no cotidiano de nossos clientes são composições de múltiplos paradigmas e o quanto esta composição de paradigmas traz de possibilidades de criação de novos territórios existenciais, e traz, simultaneamente, possibilidades de identificarmos mecanismos de captura, de adoecimento. Avaliamos que esta análise pode potencializar a clínica da terapia ocupacional. Dentro desta composição de paradigmas, a empiria, enquanto um dos elementos dessa composição, muitas vezes nos coloca diante de novas descobertas; mas descuidados da potência que a empiria pode conter, ou tratamos de classificar as novas descobertas dentro de procedimentos e técnicas já consagrados e legitimados ou a despotencializamos por não tratarmos a empiria com o rigor que lhe compete. Esquecemos que a empiria, ao ser tratada com o rigor pode transformar-se em ato de criação. Criação de novos conceitos, criação de novos entendimentos sobre clínica. O que pretendemos é acentuar a necessidade de nos afastarmos dos sentimentos e das atitudes de sujeitos/profissionais faltosos, quando nossas práticas não se 'enquadram' numa determinada teoria ou metodologia de um paradigma científico: ousar lançarmonos à produção do novo, sem que com isso percamos o rigor da análise dos nossos fazeres é necessário. É preciso deixar claro que a esquizo-ocupação não se refere a um relativismo. Ao contrário: coloca-nos diante do compromisso de acompanhar com crítica permanente aquilo que produzimos com os nossos múltiplos fazeres em terapia ocupacional.

Verificamos que, para o exercício da esquizoocupação, é preciso afastarmo-nos da concepção cartesiana que coloca a existência de um sujeito pensante como fundador do mundo, sujeito de onde tudo provém. A relação sujeito-objeto perde sua relevância, afirmando uma relação de múltiplos elementos não hierarquizados.

Assim, no agenciamento terapeuta ocupacional, cliente, atividade, materialidades, histórias de vida, histórias sociais, histórias econômicas, é preciso cartografar constantemente os efeitos de tais engendramentos, engendramentos sempre circunstanciais.

Para muitos profissionais, a esquizo-ocupação poderia soar não científica, e levaria a terapia ocupacional para o caos total. 'Como produzir uma terapia ocupacional séria e reconhecida sem usar as metodologias próprias da ciência?', nos argüiriam outros. Estes discursos e pensamentos revelam um embate de forças, uma busca pelo poder no qual todas as instituições devem ser colocadas em análise, inclusive a terapia ocupacional. Entendemos que a terapia ocupacional poderá e deverá se utilizar dos saberes científicos; mas não apenas deles, porém de muitos saberes como os estéticos, os econômicos, os políticos etc.

Quando tomamos então a terapia ocupacional a partir da noção de plano, de multiplicidade, de transdisciplinaridade, enfim de múltiplos paradigmas, pensamos se não seria um problema apontar as atividades como um especialismo da terapia ocupacional, uma vez que estaríamos delimitando um certo modo de operar a clínica. Entretanto, mais uma vez, poderemos recorrer à esquizo-ocupação para operar uma análise da instituição Terapia Ocupacional. Pois se tomarmos as atividades, as ocupações como algo sempre vivo, mutável, diverso, plural, como um plano de forças heterogêneas, a terapia ocupacional poderia reverberar, de alguma forma, maneiras de operar a clínica. As atividades, as ocupações, então, seriam exercícios de se pensar a multiplicidade da terapia ocupacional.

Queremos chamar a atenção para a necessidade de cartografar a todo momento os efeitos dos fazeres e saberes como força clínica na terapia ocupacional. Somente diante deste exercício cartográfico podemos então colocar em análise as distintas instituições, inclusive a própria instituição terapia ocupacional. A partir destes exercícios cartográficos, entendemos que a esquizo-ocupação não desqualifica os procedimentos e conceitos tradicionais da terapia ocupacional, mas desestabiliza, sim, suas pretensões à universalização, à atribuição identitária de um valor de verdade às questões de nossa clínica.

Deste modo, é necessário um grande rigor para a criação de metodologias regionais, singulares. Precisamos criar um processo exaustivo de novas cartografias e novas análises. Conscientes de que todo saber, com suas legitimidades, conceitos, discursos, pragmáticas é constituído historicamente, compreendemos que sua existência se deve a estratégias políticas, econômicas de interesses diversos e, portanto, passível de novas análises e novos questionamentos. O lugar neutro e descompromissado, a-político da clínica não existe. Todos os procedimentos e escolhas 
sãoengajados com o lugar de produção de mundo, de uma política, tenhamos ou não conhecimento disto. Colocar em análise nossos saberes não é a possibilidade de não usá-los, de desqualificá-los, nem mesmo de abolir o uso de metodologias. Colocar em análise é justamente reposicioná-los em outros sentidos, ou melhor, criar novos sentidos para tais saberes e, talvez, assim, criar novos saberes. Neste trânsito de roubar potências e conceitos, produzem-se resistências às e nas formatações históricas e políticas. Tradição e inovação aqui, então, não se constituirão em valores antagônicos, mas em processo de uma mesma produção.

Colocar-se constantemente em análise é um compromisso tenso e intenso, que cria no profissional uma instabilidade. Suportar tal instabilidade é evitar fechar-se em metodologias consagradas e estruturadas numa 'surdez etnocêntrica'.

Toda análise da esquizo-ocupação deve observar territórios, paisagens. É na rede do fazer que a atividade se abre e ganha sentidos múltiplos. Para isso é preciso sempre avaliar a atividade, o fazer, os conceitos da terapia ocupacional, outras instituições que atravessam este processo ? inclusive o próprio terapeuta ocupacional. Esta instabilidade não é um habitat exclusivo da terapia ocupacional. Percebemos que nesta insuportabilidade de passagem pelo caos, os saberes, as profissões, inclusive a terapia ocupacional, muitas vezes se rendem aos modelos formatados pelos saberes hegemônicos, criando metodologias que beiram a uma espécie de 'fundamentalismo científico'. Queremos afirmar que há aqui uma tensão para a terapia ocupacional: estar em exercício constante de análise, estar produzindo metodologias singulares, inventando trilhas ainda não trilhadas como exercício da esquizoocupação é potencializar uma terapia ocupacional crítica e ética. Tal atividade poderá sugerir? para nosso pavor? que a terapia ocupacional é um saber desqualificado, não sistematizado, classificado como precário de fundamentos teóricos. É um confronto gigantesco a que não podemos mais nos furtar. É um exercício de militância, de criação de novas possibilidades no mundo. Identificamos ser necessária a criação de estratégias para, no confronto entre as distintas instituições que nos atravessam, sobrevivermos às batalhas criando novas formas de existência. Diante do que colocamos, reafirmamos a faceta política para o que propomos como esquizo-ocupação.

Para finalizar, entendemos a esquizo-ocupação como maneira de colocar em análise a instituição Terapia Ocupacional, a fim de compor ética e esteticamente uma profissão com vistas a criar novos modos de existência, múltiplos territórios existenciais: esquizoocupação como apropriação da abordagem da diferença, apropriação do múltiplo em terapia ocupacional.

COSTA M. C.; ALMEIDA, M. V. M. 'Schizo-occupation': a tool for the analysis of the institution Occupational Therapy. Rev. Ter. Ocup. Univ. São Paulo, v. 15, n. 1, p. 11-6, jan./ abr., 2004.

\begin{abstract}
This article presents the concept-exercise 'schizo-occupation' as a tool for the analysis of the institution 'occupational therapy'. Taking inspiration from the schizoanalysis and from the analysis of how occupational therapy as an institution is being built as a field of knowledge, the concept-exercise 'schizo-occupation' is not presented as a truth-attached Model that would rule techniques and/or procedures; on the contrary, 'schizo-occupation' seeks to work as a tool for an everyday analysis in 'occupational therapy'. The employment of this tool aims to make possible the coming up of ethical and political attitudes in a social-compromised profession, in a profession designed not to serve to any hegemonic interest. Hence, the conceptexercise 'schizo-occupation' will be taken to urge a kaleidoscopial view of activities, of models, of methods. This concept intends to provoke, to surprise the so-called activity-analysis. A provocation that hopes to work with innumerable looks, innumerable meanings of our so beloved 'occupational therapy'.
\end{abstract}

KEY WORDS: Occupational therapy/trends. Professional practice/trends. Psychoanalisis/ trends. 


\section{REFERÊNCIAS}

BAREMBLITT, G. Introdução à esquizoanálise. Belo Horizonte: Biblioteca do Instituto Félix Guattari, 1998.

GUATTARI, F. Caosmose: um novo paradigma estético. Rio de Janeiro: Editora 34, 1993.

PASSOS, E.; BARROS, R. B. A construção do plano da clínica e o conceito de transdisciplinaridade. Psicol. Teoria Pesq., v. 16, n. 1, p. 71-9, 2000.
RAUTER, C. Clínica do esquecimento: construção de uma superfície. 1998. Pontifícia Universidade Católica, São Paulo, 1998. Dissertação (Mestrado).

RODRIGUES, H. B. C.; Souza, V. L. de. A análise institucional e a profissionalização do psicólogo. In: KAMKhagi, V. R.; SAIDON, O., orgs. Análise Institucional no Brasil. Rio de Janeiro: Rosa dos Ventos, 1991, p. 27-46. 